\title{
The Mediation Effect of Leader Support in the Effect of Organizational Commitment on Job Satisfaction: A Research in the Turkish Textile Business
}

\author{
Saadet Ela Pelenk \\ Recep Tayyip Erdogan University, Rize, Turkey
}

\begin{tabular}{l} 
Keywords: \\
Organizational Commitment, \\
Job Satisfaction, Leader \\
Support, Motivation \\
\hline Received \\
09 October 2020 \\
Received in revised form \\
17 October 2020 \\
Accepted \\
18 October 2020 \\
\hline
\end{tabular}

*Correspondence:

epelenk@yahoo.com

\section{ABSTRACT}

Organizational commitment is a psychological concept that expresses the feelings of belonging and loyalty. Commitment and leader support can increase job satisfaction, but factors such as economic crises, epidemics, globalization increase socio-economic problems such as unemployment and productivity loss. In this context, leader support such as career development, information sharing, feedback and finding solutions to the problem may cause employees to feel valuable and to make effort. This research shows that a leader-manager is the person who not only maintains the current period but also understands employee behaviors and reactions. As an effect of this research, employees do not see their job as compulsory, but find it meaningful and consequently job satisfaction may increase. The purpose of this research is to examine the mediating effect of leader support in the effect of organizational commitment on job satisfaction. For this purpose, a questionnaire was completed by 126 blue-collar workers $(\mathrm{N}=150)$ in textile company in Istanbul. In the analysis of research data, SPSS 21 statistical software and multiple regression method were used. As a result of the research, the mediating role of leader support in the effect of organizational commitment on job satisfaction has been determined. This research, is based on neo-classical management approach, contributes to the scientific management literature and human resources managers in order to increase the productivity of business and employee in cooperation with leaders and employees.

CCIKD Publishing

Organizational commitment as a positive individual orientation integrates the goals and objectives of the employee and the organization (Blau \& Boal, 1987). Organizational commitment is an issue that has attracted the attention of researchers since the 1950s. Organizational commitment was examined for the first time in Whyte's (1956) "The Organizational Man" publication. Porter, Steers, 
Mowday and Boultian (1974) also developed the organizational commitment scale. According to Mowday, Porter and Steers (1982), organizational commitment is an employee's belief on the goals and targets of the organization. Therefore, the employee works hard for the organization and wants to stay as a member. Ultimately, organizational commitment enables the employee to integrate with the goals of the organization and to internalize the organizational values of the organization (Brewer, 1996). In fact, commitment to the organization is a psychological condition that explains the employee's relationship with the organization (Allen \& Grisaffe, 2001).

Employee's organizational commitment is to work with emotional commitment by adopting organizational goals and norms (Allen \& Meyer, 1996). Organizational commitment was described by Becker (1960) as "conscious bias", by O'Reilly and Chatman (1986) as "adaptation, identification and internalization" and by Meyer, Allen and Smith (1993) as "normative, emotional and continuation commitment". Normative commitment, one of the types of organizational commitment, is the continuation of the organization membership that the employee believes ethically and right; emotional commitment is that the employee feels himself/herself as a part of the organization and wants to stay in the organization because the organization has meaning for him/her (Allen \& Meyer, 1990). According to Wiener (1982), if there is a harmony between individual and organizational values, emotional commitment increases. On the other hand, if the employee feels obliged to work due to the increase in cost and lack of job opportunities, continuance commitment occurs (Allen \& Meyer, 1990). At this point, the employee is there not because he/she really wants to, but because he/she has to work economically.

The relationships between organizational commitment and various variables (Makanjee, Hartzer, \& Uys, 2006; Markovits, Davis, \& Van Dick, 2007; Odoch \& Nangoli, 2014; Rose, Kumar, \& Pak, 2009; Peng, Li, Zhang, Tian, Miao, Xiao, \& Zhang, 2016; Reid, Riemenschneider, Allen, \& Armstrong, 2008; Sneed \& Herman, 1990; Yoon \& Thye, 2002) provide positive work outcomes. As employees affiliated with their organizations are more satisfied with their jobs (Markovits et al., 2007; Yousef, 2000); their job efficiency increases (Odoch \& Nangoli, 2014), their job involments increase (Reid et al., 2008), their burnout decrease (Peng et al., 2016) and their organizational learning increase (Rose et al., 2009). On the other hand, leadership behaviors and style positively affect employees' commitment on the organization (Hulpia, Devos, \& Van Keer, 2009; Leow \& Khong, 2009; Yousef, 2000). Thus, the performance of the employees increases (Mayer \& Schoorman, 1992; Ward \& Davis, 1995) and this situation is important for the organization to achieve its sales targets and profitability (Benkhoff, 1997).

Organizational commitment affects the employee's job satisfaction (Bateman \& Strasser, 1984; Romzek, 1989). The satisfaction of the employees will also increase their performance. Employees who are satisfied with their job tend to be collaborative, helpful, respectful and considerate (Wilson \& Frimpong, 2004). According to Locke (1976), job satisfaction is the positive feeling felt by employees as a result of evaluating their job or work experiences. According to Mowday et al. (1982), organizational commitment and job satisfaction are different concepts. Organizational commitment is related to goals and values of the organization and job satisfaction is related to the job description that includes responsibilities of the employee.

In the literature, job satisfaction has been examined with leader effectiveness and intention to quit (Amundsen \& Martinsen, 2014), personality traits of the leader (Agnes, Kiarie, Maru, \& Cheruiyot, 2017), organizational support and leader behavior (Ahmad \& Yekta 2010), 
organizational culture and leadership behavior (Tsai, 2011), leadership behavior (Osborn \& Vicars, 1976), and leadership behavior and trust (Gilstarp \& Collins, 2012).

In every institution, one person must undertake the management. This person should make the decisions, know and follow the activities related to the corporate vision. Every organization needs to be managed, but it is the management style that matters. In the hierarchical management approach, pressure and blame may occur from the employers to the employee. In this management style, a culture of control and fear prevails in words, spatial order, looks, movements and tone of voice. However, in the participative management approach, the employers see themselves as a part of the employees. In this approach, "employees will succeed together. If employees fail, the responsibility belongs to all of them, not one person". A leader who has the "consciousness of us" has a positive, accommodating, responsible, supportive, honest personality that sees every employee as a part of the system (Cüceloğlu, 2001). Leader support in this management approach means that the leader values the employee and makes the employee feel valued (Cho, Johanson, \& Guchait, 2009; Cüceloğlu, 2001). Omidifar (2013) found that leadership (management) style positively and significantly affected job satisfaction and organizational commitment in his research on the Iranian education sector. In the related study, it was suggested to provide working environments where teachers would increase their potential.

In the literature, the relationship between leadership support, organizational commitment and job satisfaction has been examined (Currivan, 1999; Griffin, Patterson, Malcolm, \& West, 2001; Seo, Ko, \& Price, 2004; Wilson, 1995). The aim of this research is to examine the mediating role of leader support in the effect of organizational commitment on job satisfaction. In fact, organizational commitment can be expected to increase job satisfaction. However, factors such as competition, globalization and technology can put employees under a heavy workload. On the other hand, employees who have to work economically and socially can only feel the continuance commitment to their organization. In this context, the employees will only do the work included in the job description and leave the workplace quickly. In these types of employees, there will be a decrease in work output such as job satisfaction and performance. According to the research conducted by Çelen, Teke and Cihangiroğlu (2013) with healthcare professionals, it was found that emotional and normative commitment increased employees' job satisfaction, but continued commitment did not affect job satisfaction.

The main problem of this research is that textile workers do not feel organizational commitment or only feel continuance commitment because they have to work for reasons such as minimum wage and exhausting working hours. Therefore, when workers complete their shift time, they leave the business immediately. The monotonous and tiring work process hinders the job satisfaction of the employees. This situation may cause the worker to work inefficiently and leave the job. However, a leader who supports workers, adds value and awareness to them, can improve the quality of organizational commitment and job satisfaction. This situation can positively affect the work efficiency and creativity of the worker; on the other hand, the profitability of the organization. The question addressed by this research is, does leader support have a mediating role in the effect of organizational commitment on job satisfaction, especially in working for economic reasons?

In the management evolution from Taylor's Scientific Management approach to the NeoClassical management approach of Elton Mayo, that the employee is seen as a "human factor" instead of a mechanical approach such as a production factor. At this point, leader support increases employee development and job satisfaction with effective communication between employee and 
leader. As a result of the destructive competition of today's businesses, negative situations such as the risk of dismissal, minimum wage, excessive workload are occurred. Under these conditions, it is not possible to be satisfied with the work with organizational commitment.

The present research has clarified this dilemma with the support of the leader. When the literature is examined, there are many studies examining organizational commitment and job satisfaction, as well as organizational support and job satisfaction. However, there is no study examining the mediating role of leader support in the relationship between organizational commitment and job satisfaction. Another aspect of the research is to take the opinions of bluecollar workers working in a sector with employment problems such as downsizing, merger and liquidation. Problems such as economic crises, diseases and epidemics (Covid-19) experienced in the world in the 2020s have liquidated many companies and brought many of them to the point of closing. If there are still employees who can hold on to their jobs, it is definitely thanks to the support of their leader. The contribution of this study to researchers is that leadership support and value given to workers reduce job difficulties and increase job satisfaction. In this context, leadership ability is important, thus increasing worker's productivity and contribution to the business in a constructive way.

\section{Hypothesis Development}

Job satisfaction is the positive response of an employee when evaluating all or certain aspects of a job or satisfaction with job duties (Hugnes, Gonnett, \& Curphy, 2006). Bhuian, Al-Shammari and Jefri (1996) found that organizational commitment affects job satisfaction in their research with 504 expatriate employees in Suuidi Arabia. According to this, expatriate workers are people from different parts of the world who come to work and have a high turnover of labor. For this reason, short-term working conditions reduce job satisfaction and performance as long as there is no commitment to the organization. Kim, Leong and Lee (2005) examined the relationship between employees' service orientation and their job satisfaction, organizational commitment, and intention to quit in a study conducted in Chinese restaurants. As a result of the research, job satisfaction is positively associated with organizational commitment, and organizational commitment and job satisfaction reduce the intention to quit.

As organizational commitment is one of the important factors for the organization to achieve its goals; businesses want to increase organizational commitment (Çalışkan, 2015). According to the management development model (Pool \& Pool, 2007), organizational commitment leads to job satisfaction. In the relevant model; organizational commitment primarily affects employee's motivation. At this point, organizational commitment will affect the effort-performance expectation of the employee and the effort-performance expectation will affect the performance-work output expectation. These expectations will also create job satisfaction and learning organization (Pool \& Pool, 2007). Organizations that make learning, education and development a priority will provide more profitability and job satisfaction (Leslie, Aring, \& Brand, 1998). Odoch and Nangoli (2014) examined the effect of organizational commitment on job satisfaction in Uganda Commerce Colleges. As a result of the research, a positive relationship was found between organizational commitment and job satisfaction. Markovits et al. (2007) examined organizational commitment profiles and job satisfaction in their research with Greek public and private sector employees. As a result of the research; emotional commitment has been found to increase internal and external job satisfaction. The $\mathrm{H}_{1}$ hypothesis based on related studies is as follows:

$\mathbf{H}_{1}$ : Organizational commitment has a positive and significant effect on job satisfaction. 
Psychologist Cüceloğlu (2001) stated that when people are not honored, supported and appreciated, they will enter a negative mood and begin to lose their trust. In this context, loss of trust leads to more cautiousness, fear of doing something wrong, and withdrawn. This type of employee starts to attract the attention of the employer and to receive negative reviews. On the contrary, the person whose work is honored and supported, gets rid of the depression and makes an effort. However, some managers see the criticism more correctly with the idea that "if I appreciate and support it, my employee will be spoiled." On the other hand, according to George (2008), a leader should encourage all employees and increase their motivation to increase efficiency. The quality of the leader-member relationship is also related to task performance (Hui, Law, \& Chen, 1999) and organizational commitment (Green, Anderson, \& Shivers, 1996). Organizational commitment is a voluntary action and employees gain a meaning when they are devoted to the organization. On the contrary, it is a wrong strategy for managers to try to establish organizational commitment by commanding or forcing employees (Bakan, 2011). Singh (2000) found a positive relationship between supervisor support and organizational commitment in call center employees. Walumbwa, Orwa, Wang and Lawler (2005) and Wilson (1995) found a positive relationship between organizational commitment and leader support. Based on these explanations, the $\mathrm{H}_{2}$ hypothesis was developed:

$\mathbf{H}_{2}$ : Organizational commitment has a positive and significant effect on leader support.

In the contemporary business environment, the most important organizational resource is human potential and every organization needs a strong leader. In this respect, the main factors for the success of the organization are effective leader and employee satisfaction (Agnes et al., 2017). Amundsen and Martinsen (2014) found that a leader's empowering behaviors and leadership effectiveness are related to job satisfaction and intention to quit. In this context, the leader can support its employees with 360 degrees and forward feedback programs. On the other hand, leaders can support employees by gaining positive business attitudes, caring about the needs of employees and encouraging them towards organizational goals. In addition, leader can show their support by seeing the contributions of employees, communicating with them and treating them fairly and respectfully (Ackfeldt \& Coote, 2005).

Leadership support (Bhanthumnavin, 2003), which expresses the positive work relationship between employer and employee, can increase the effect of organizational commitment on job satisfaction. To act in accordance with the organization's goals and policies, spending his/her energy for the organization and prioritizing organizational interests are signs of organizational commitment. Thus, employers can contribute to organizational productivity by identifying with the organization of the employee (Başaran, 1982). The increase in organizational productivity depends on job satisfaction. At this point, employees who are satisfied with their job and love their job can be productive in an organization (Tütüncü, 2000). If the main objectives of businesses are to survive and to make profit, efficiency is a driving force for these basic purposes. For this purpose, leader and friend support increases both job satisfaction and productivity of employees (Babin \& Boles, 1996).

The relationship between leader and employee is critical to effective leadership. This style of leadership allows the employee to gain experience, autonomy and self-efficacy. Previous studies on leaders show that leadership support and favorable working conditions highly increase job satisfaction (Van Voorhis, Cullen, Link, \& Wolfe,1991). 
Tsai (2011) examined organizational culture, leader behaviors and job satisfaction in a survey research with 200 nurses. The results revealed that leader behaviors positively affect the job satisfaction of the employees. In addition, it has been determined that leader traits such as extraversion, emotional balance, conscientiousness and adaptability increases job satisfaction (Agnes et al., 2017).

Currivan (1999) examined the relationship between employee turnover, job satisfaction and organizational commitment; Griffin et al. (2001) examined the relationship between job satisfaction, teamwork and leader support; Seo et al. (2004) examined the determinants of job satisfaction. As a result of all these studies, it has been determined that leader support increases job satisfaction. According to Chiok (2001), the leader's job satisfaction enhancing features are to appreciate and thank, to meet the needs of the employees, to help and guide the employees, to use leadership skills to meet the needs of the unit and to support the teams. Based on these explanations, the $\mathrm{H}_{3}$ hypothesis was developed:

H3: Leadership support has a positive and significant effect on job satisfaction.

Leader support refers to the value given to the employee and the supportive organizational culture. Employees have some perceptions of leader support. These perceptions are related to the contribution of the employees to the business and the leader thinking about the welfare of the employees (Eisenberger, Stinglhamber, Vandenberghe, Sucharski, \& Rhoades, 2002). In humanoriented businesses (for example, service businesses), leaders learn what employees feel and what they need (Liao, Hu, \& Chung, 2009). However, employees may not always be devoted to their organizations. Living conditions or limited job opportunities may force employees to stay in their current job. At this point, continuance commitment can create job dissatisfaction and may cause different responses. These responses can be listed as coming to work late, disrupting work or not coming to work, complaining about their job, showing poor performance, not taking responsibility and causing harm to the organization. Since all these responses are related to variables such as productivity, organizational or individual performance, they also affect the variables of organizational commitment and job satisfaction (Vecchio, 1995). Liao et al., (2009) identified the mediating effect of job satisfaction between leader-member relationship and organizational commitment in the Taiwan tourism industry.

Job satisfaction is the feeling of happiness as a result of evaluating the general attitude towards the job and experience (Locke, 1976). The business environment and the leader's attitude can positively affect job satisfaction. Leadership style is one of the organizational factors that affect organizational commitment because it concerns the goals and objectives of the organization. On the other hand, job satisfaction which is positively influenced by leader support (Currivan, 1999; Griffin et al., 2001; Seo et al., 2004) is related to the employee's job responsibilities (Mowday et al.,1982). In this context, especially difficult and heavy professions force employees to survive rather than job satisfaction. Working in these professions arises from social and economic necessities rather than loving the job. However, leader-manager support can increase the effect of organizational commitment on job satisfaction by harmonizing the work conditions. Organizational commitment provides psychological integration, identification and inner balance (Drummond, 2000). Supporting this psychological state with leader behaviors will increase employee motivation and productivity (Rhoades \& Eisenberger, 2002). On the other hand, perceived subclinical psychopathy of the leader negatively affects the organizational commitment and job satisfaction of 
subordinates (Sanecka, 2013). Chiok (2001) determined that leader behaviors were positively associated with job satisfaction (29\%), productivity (9\%) and organizational commitment (22\%) in the study with nurses and their managers in Singapore. According to Lam, Zhang and Baum (2001), leaders are effective in employees' organizational commitment and job satisfaction. Based on these explanations, the $\mathrm{H}_{4}$ hypothesis was developed:

H4: Leader support has a mediating effect on the relationship between organizational commitment and job satisfaction.

\section{The Study}

The aim of the research is to examine the mediating role of leader support in the effect of organizational commitment (emotional, normative and continuance commitment) on job satisfaction. Under normal conditions, it is possible for organizational commitment to positively affect job satisfaction. However, it is possible that job opportunities may decrease due to economic crises, downsizing, disease-epidemic reasons, or employees may see their jobs as compulsory. Can those who work under these conditions be satisfied even if they come to work with the feeling of obligation? This research examines the mediating role of leader support in this contradictory situation. The target of this study is to determine the effect of leader support on job satisfaction in occupations that are at risk of dismissal, workers who have to work periodically or economically but are affiliated with the organization. The research questions are formed as follows:

1. Does organizational commitment have a significant effect on job satisfaction?

2. Does organizational commitment have a significant effect on leader support?

3. Does leader support have a significant effect on job satisfaction?

4. Does leader support have a mediating effect on the relationship between organizational commitment and job satisfaction?

\section{Research Framework}

The conceptual model of the research is shown in Figure 1. This model measures the job behaviour and reactions of textile and clothing manufacturing employees with the support of the leader. In the conceptual model, the direct effect of organizational commitment on job satisfaction is shown through $\mathrm{H}_{1}$ (c). Based on the literature, organizational commitment is expected to have a significant impact on job satisfaction. As the second stage in the model, the direct effect of organizational commitment on leader support is shown through $\mathrm{H}_{2}$ (a). Based on the literature, organizational commitment is expected to have a significant impact on leader support. As the third stage in the model, the direct effect of leader support on job satisfaction is shown through $\mathrm{H}_{3}$ (b). Based on the literature, leader support is expected to have a significant impact on job satisfaction. As the fourth stage in the model, the indirect effect of leader support (mediation) in the effect of organizational commitment on job satisfaction is shown through $\mathrm{H}_{4}(\mathrm{c}$ "). Based on the literature, leader's support is expected to have a mediator role in the impact of organizational commitment on job satisfaction. Organizational commitment is divided into three dimensions as emotional commitment, normative commitment and continuation commitment. Emotional commitment is being satisfied with the job and continuing to be a member of the organization. Normative commitment is that the employee stays in the organization with a sense of responsibility. If the employee stays in the organization as a result of having to work, it is a continuance commitment. 


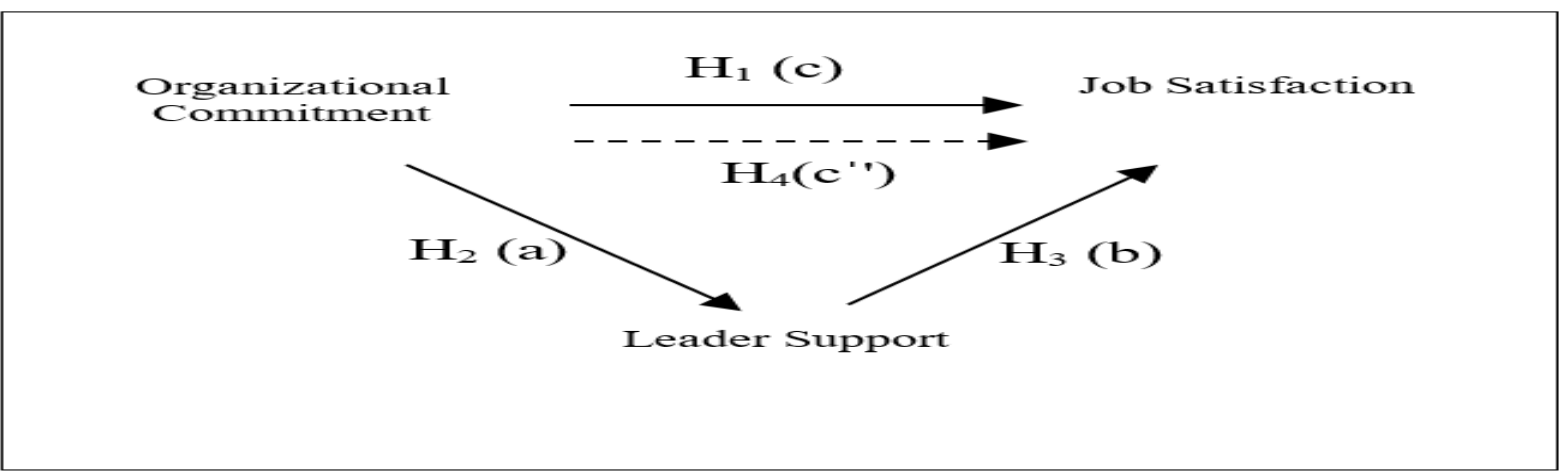

Figure 1. Conceptual model

In the model of the study to be tested, the independent variable was determined to be the organizational commitment, the dependent variable was determined to be the job satisfaction, and the mediator variable was determined to be in the relationship between the two variables (Figure 1). Baron and Kenny (1986) explained the four steps of establishing mediation as follows. The first three steps need to be tested as independent models. Accordingly, in the first step, the independent variable should have a relationship with the dependent variable (Path $\left.\mathrm{c}-\mathrm{H}_{1}\right)$. This step reveals that there is an effect that can be mediated. In the second step, the independent variable must have a relation to the mediator variable $\left(\mathrm{Path}\right.$ a $-\mathrm{H}_{2}$ ). This step essentially involves treating the mediator variable as a dependent variable. In the third step, the mediator variable must have a relation to the dependent variable (Path $b-\mathrm{H}_{3}$ ). It is assumed that the mediator variable is considered an independent variable and affects the dependent variable. It is not enough to simply associate the mediator variable with the dependent variable because the relationship between two variables may arise from the independent variable. Therefore, the independent variable should be controlled in determining the effect of the mediator variable on the dependent variable. In the fourth step, in order to determine that the mediator variable mediates the relationship between independent and dependent variables (path between independent-dependent variables "c' path"), it is necessary to determine whether it is controlled by the mediator variable. If the significance of the path "c" $\left(\mathrm{H}_{4}\right)$ in the model does not disappear, in order to reveal the indirect effect of the change arising from the mediator variable, the significance of this indirect effect can be determined by the Sobel test statistics.

\section{Method}

\section{Respondents' Profile}

In order to collect research data, questionnaires were distributed among 126 people working in an enterprise which manufacturing textile and ready-to-wear products in Istanbul/Turkey. The convenience sampling method was used to collect the research data. The presence of creativity, innovation and teamwork in the textile sector and the quality of Turkish enterprises in this sector are important in selecting the research sample. In this context, permission was obtained from the human resource manager of the enterprise. Then, 150 questionnaires ( $\mathrm{N}=$ Research Universe) were sent online to the respondents; 126 of questionnaires were filled true and completely.

In total, $60 \%$ of the respondents in the survey are male (75 people), $75 \%$ of the respondents (94 people) are married. The average age of the respondents is $37.60 \%$ of the respondents have a service period of 10 years or more, $65 \%$ of the respondents ( 81 people) are technical high school graduates, $25 \%$ are vocational school graduates, and $10 \%$ have a bachelor's degree. 


\section{Instruments}

The questionnaire consists of two parts including demographic and variable questions. In the first part of the questionnaire, questions were asked about the gender, marital status, age, length of service and educational status of the participants. In the second part of the research, Meyer and Allen's (1991) scale consisting of seventeen questions was used to measure organizational commitment. To measure leader support, Netemeyer et al.'s (1997) five-question scale was used. Weiss, Dawis, and England's (1967) nine-item scale was used to measure job satisfaction. The questionnaire was scaled according to the 5-point likert scale (1 = Strongly disagree, 2 = Disagree, 3 = Undecided, 4 = Agree, $5=$ Strongly agree).

\section{Data Analysis}

SPSS 21 and AMOS 22 program was used to analyze the data. Confirmatory factor analysis and Cronbach Alpha methods were used for the validity and reliability of the scales. Skewness and Kurtosis coefficients were used to test the normality of item scores. The fact that the skewness and kurtosis coefficients used in the normal distribution feature of the scores obtained from a continuous variable remain within \pm 1 limits can be interpreted as the scores not showing a significant deviation from the normal distribution (Büyüköztürk, 2011). Confirmatory factor analysis was performed to test whether a previously defined and restricted structure is verified as a model. After determining the validity and reliability of the scale, correlation and multiple regression analyzes were performed.

\section{Findings}

\section{Validity and Reliability Analysis Findings of the Organizational Commitment Scale}

The results obtained from the confirmatory factor analysis performed with the 17 items and 3dimensional structure of the organizational commitment scale are shown in Table 1. Cronbach Alpha technique, one of the item analysis methods, was used to examine the consistency between test scores and it is generally expected to be above .7. Item total correlation, another item analysis method, was used to explain the relationship between the scores obtained from the test items and the total score of the test, and indicated that the items in both test measurement tools exemplify similar behaviors and the internal consistency of the test is high. Item-total correlation shows to what extent the items differentiate individuals in terms of measured behavior. In general, it can be said that items with item-total correlations of .30 and higher distinguish individuals well, and items between .20-.30 can be tested when necessary (Büyüköztürk, 2011). Cronbach Alpha coefficient of the organizational commitment scale was .92; Cronbach's alpha coefficients of the subdimensions are .89 for emotional commitment, .88 for continuance commitment and .85 for normative commitment. The item-total correlation of the items in the scale was found to be between .38 and .8 . As a result of the reliability and validity analysis, it was found that the organizational commitment scale is a valid and reliable scale with 17 items and its 3-dimensional structure.

According to the results of the confirmatory factor analysis, GFI and RMSEA values of the model fit indices were not at appropriate levels, but the factor loadings were higher than .40; SCR $>.70$ and AVE > .50 were found. For this reason, first of all, fit covariance connections and fit indices were tried to be improved and with covariance connections (m1-m5, m2-m3, m3-m4, m7$\mathrm{m} 8, \mathrm{~m} 8-\mathrm{m} 9, \mathrm{~m} 10-\mathrm{m} 12, \mathrm{~m} 13-\mathrm{m} 14, \mathrm{~m} 14-\mathrm{m} 15)$. It was determined that only the GFI index did not reach the appropriate value. Considering that the GFI index is sensitive to the sample size and the degree of freedom (Çokluk, Şekercioğlu, \& Büyüköztürk, 2010), it was deemed sufficient to have 
a perfect level of 7 fit indices except for GFI, since the number of items in the scale was high and the sample size was 126 , without requiring any item deletion.

Table 1

Validity and Reliability Analysis Findings of the Organizational Commitment Scale

\begin{tabular}{|c|c|c|c|c|c|}
\hline Item and Factor & Std. $\beta$ & $t$ & $R^{2}$ & $r$ & $\alpha(.92)$ \\
\hline \multicolumn{6}{|c|}{ Emotional Commitment } \\
\hline M1 & .90 & & .80 & .74 & \multirow{6}{*}{.89} \\
\hline M2 & .84 & $14.32^{* *}$ & .71 & .62 & \\
\hline M3 & .85 & $12.63^{* *}$ & .72 & .47 & \\
\hline M4 & .80 & $12.89^{* *}$ & .64 & .38 & \\
\hline M5 & .86 & $15.00 * *$ & .74 & .80 & \\
\hline M6 & .91 & $17.21^{* *}$ & .83 & .74 & \\
\hline \multicolumn{6}{|c|}{ Continuance Commitment } \\
\hline M7 & .90 & & .81 & .63 & \multirow{6}{*}{.88} \\
\hline M8 & .81 & $15.81^{* *}$ & .65 & .61 & \\
\hline M9 & .72 & $10.81^{* *}$ & .51 & .49 & \\
\hline M10 & .72 & $10.53^{* *}$ & .51 & .57 & \\
\hline M11 & .83 & $14.32 * *$ & .70 & .58 & \\
\hline M12 & .94 & $18.69^{* *}$ & .88 & .64 & \\
\hline \multicolumn{6}{|c|}{ Normative Commitment } \\
\hline M13 & .96 & & .92 & .67 & \multirow{5}{*}{.85} \\
\hline M14 & .92 & $20.98^{* *}$ & .84 & .56 & \\
\hline M15 & .80 & $12.27 * *$ & .64 & .41 & \\
\hline M16 & .73 & $11.89^{* * *}$ & .54 & .58 & \\
\hline M17 & .81 & $14.76^{* *}$ & .66 & .72 & \\
\hline \multicolumn{6}{|c|}{ Fit Index } \\
\hline $\mathrm{X}^{2} / \mathrm{sd}$ & 1.38 & & NNFI & .96 & \\
\hline RMSEA & 0.05 & & $\mathrm{CFI}$ & .97 & \\
\hline SRMR & 0.06 & & SCR & .95 & \\
\hline GFI & 0.88 & & AVE & .56 & \\
\hline
\end{tabular}

** $p<.01 ; \quad r=$ Total item correlation

\section{Validity and Reliability Analysis Findings of the Job Satisfaction Scale}

The results obtained in the confirmatory factor analysis performed with 9 items and onedimensional structure of the job satisfaction scale are shown in Table 2. According to the confirmatory factor analysis results, factor loads are higher than .40; SCR > .70 and AVE > .5. SCR (Scale Composite Reliability) is the method that includes the added variances of the observed independent variables. SCR is expected to be calculated separately for subscales and to be greater than .7. AVE (Average Variance Extracted) has been proposed as a measure of convergent validity. If it is used with SCR and the SCR is $\geq .7$. it is acceptable that the AVE is .50 and it will be a strong indicator of convergent validity. If the AVE value is less than .5. the variance of the measurement error is greater than the variance of the construct, and therefore, construct validity may not be accepted as is the case with the validity of individual indicators. AVE value is a more conservative measure than construct reliability (i.e., CR). Even if the variance of the measurement error is greater than .5. it is stated that if only the $\mathrm{CR}$ value is taken into account, its convergent validity is acceptable (Fornell \& Larker, 1981).

It was determined that the $\mathrm{t}$ values of the factor loads for all of the items in the scale were significant $(p<.01)$ and the contribution of the items to the variance ranged from .80 to .95 . The Cronbach Alpha coefficient of the scale was .96, and the item-total correlation of the items in the scale ranged from .89 to .93 . According to the results of the reliability and validity analysis, it was found that the job satisfaction scale is a valid and reliable scale with 9 items and its one-dimensional structure. 
Table 2

Validity and Reliability Analysis Findings of the Job Satisfaction Scale

\begin{tabular}{ccccc}
\hline Item & Std. $\beta$ & $t$ & $R^{2}$ & $r$ \\
\hline M1 & .95 & $18.97^{* *}$ & .89 & .89 \\
M2 & .91 & $14.91^{* *}$ & .84 & .87 \\
M3 & .79 & $12.89^{* *}$ & .63 & .76 \\
M4 & .84 & $13.01^{* *}$ & .71 & .81 \\
M5 & .80 & $7.78^{* *}$ & .64 & .80 \\
M6 & .59 & $8.26^{* *}$ & .35 & .60 \\
M7 & .62 & $12.02^{* *}$ & .38 & .63 \\
M8 & $13.75^{* *}$ & .59 & .78 \\
M9 & .77 & Fit Index & .67 & .81 \\
\hline X $/$ sd & .82 & & NNFI & .96 \\
RMSEA & 1.85 & CFI & .97 \\
SRMR & 0.08 & SCR & .93 \\
GFI & 0.03 & AVE & .63 \\
\hline * $p<.01 ; r=$ Total item correlation & & &
\end{tabular}

\section{Validity and Reliability Analysis Findings of Leader Support Scale}

The results obtained in the confirmatory factor analysis performed with 5 items and onedimensional structure of the leader support scale are shown in Table 3. As a result of the confirmatory factor analysis, SCR $>.70$ and AVE $>.5$. It was determined that the t values of the factor loads for all of the items in the scale were significant $(p<.01)$ and the contribution of the items to the variance ranged from .26 to .90. The Cronbach Alpha coefficient of the scale was .90. and the item-total correlation of the items in the scale ranged from .55 to .87 . According to the results of the reliability and validity analysis, it was found that the leader support scale is a valid and reliable scale with its 5-item and one-dimensional structure.

Table 3

Validity and Reliability Analysis Findings of the Leader Support Scale

\begin{tabular}{lccccc}
\hline Item & Std. $\beta$ & $t$ & $R^{2}$ & $r$ & $\alpha$ \\
\hline M1 & .94 & & .89 & .86 & .79 \\
M2 & .83 & $13.99^{* *}$ & .68 & .55 & .90 \\
M3 & .51 & $11.32^{* *}$ & .56 & .74 \\
M4 & .75 & $6.32^{* *}$ & .26 & .87 & \\
M5 & .95 & $2.25^{* *}$ & .90 & & .98 \\
\hline & & Fit Index & NNFI & .99 \\
X'/sd & 1.82 & & CFI & .90 \\
RMSEA & 0.08 & SCR & .65 \\
SRMR & 0.01 & AVE & \\
GFI & 0.98 & & &
\end{tabular}

** $p<.01 ; r=$ Total item correlation

\section{Descriptive Statistics of Scales}

Descriptive statistics of the scale scores are presented in Table 4. The average score of the organizational commitment scale is $3.73 \pm .73$; the mean score of the job satisfaction scale was determined as $3.65 \pm .98$ and main score of the leader support scale was determined as $3.80 \pm .93$. It can be said that the level of satisfaction and the perception of leader support is medium-high.

Table 4

Descriptive Statistics of the Scale and Sub-dimension Scores

\begin{tabular}{|c|c|c|c|c|c|c|c|}
\hline Scale & $\mathrm{N}$ & Min. & Max. & $\overline{\mathrm{X}}$ & SS & Skewness & Kurtosis \\
\hline Emotional Commitment & 126 & 1.33 & 4.83 & 3.75 & .90 & -.87 & -.32 \\
\hline Continuance Commitmet & 126 & 1.17 & 5.00 & 3.82 & .85 & -.49 & -.27 \\
\hline Normative Commitment & 126 & 1.20 & 4.80 & 3.60 & .90 & -.98 & -.17 \\
\hline Organizational Commitmet & 126 & 1.94 & 4.53 & 3.73 & .73 & -.85 & -.61 \\
\hline Job Satisfaction & 126 & 1.56 & 4.56 & 3.65 & .98 & -1.06 & -.42 \\
\hline Leadership Support & 126 & 1.20 & 5.00 & 3.80 & .93 & -.70 & -.30 \\
\hline
\end{tabular}




\section{Findings Regarding the Research Model}

The results of the Pearson correlation analysis between the scale scores were given in Table 5. A positive and significant relationship was found between organizational commitment and job satisfaction $(r=.52 ; p<.05)$ and leader support $(r=.54 ; p<.05)$. A positive and significant relationship was found between job satisfaction and leader support $(r=.74 ; p<.05)$.

Table 5

Relationship Between Scale Scores

\begin{tabular}{|c|c|c|c|c|c|c|}
\hline Scale and Sub-Dimension & 1 & 2 & 3 & 4 & 5 & 6 \\
\hline 1-Emotional Commitment & 1 & $.46 * *$ & $.55^{* *}$ & $.83 * *$ & $.48 * *$ & $.53 * *$ \\
\hline 2-Continuance Commitment & & 1 & $.46^{* *}$ & $.78 * *$ & $.31 * *$ & $.34 * *$ \\
\hline 3-Normative Commitment & & & 1 & $.82 * *$ & $.50 * *$ & $.50 * *$ \\
\hline 4-Organizational Commitment & & & & 1 & $.52 * *$ & $.54 * *$ \\
\hline 5-Job Satisfaction & & & & & 1 & $.74 * *$ \\
\hline 6-Leadership Support & & & & & & 1 \\
\hline
\end{tabular}

Table 6 includes findings and hypothesis results regarding the model tests performed in accordance with Baron and Kenny's (1986) steps. As presented in Table 6, as the first hypothesis of the research, organizational commitment had a significant effect on job satisfaction $(\beta=.67 ; t=$ 6.17; $p<.05)$ and $\mathrm{H}_{1}$ (c) hypothesis was accepted. As the second hypothesis of the study, organizational commitment had a significant effect on leader support $(\beta=.71 ; t=6.57 ; p<.05)$ and $\mathrm{H}_{2}$ (a) hypothesis was accepted. As the third hypothesis of the study, leader support had a significant effect on job satisfaction $(\beta=.84 ; t=12.73 ; p<.05)$ and $\mathrm{H}_{3}(\mathrm{~b})$ was accepted. And as the fourth hypothesis of the research, leader support had a mediating effect on the relationship between organizational commitment and job satisfaction $(\mathrm{ES}=.59 ; \mathrm{SBT}=5.86 ; p<.05)$ and $\mathrm{H}_{4}$ (c') was accepted. In this context, in the relationship between organizational commitment and job satisfaction, a $37 \%$ change occurs in job satisfaction with the mediation effect of leader support $\left(\mathrm{R}^{2}=.37\right)$.

Table 6

Results Regarding the Research Model with Mediator Variables

\begin{tabular}{|c|c|c|c|c|c|c|c|}
\hline & Independent Valuable & Path & Dependent Valuable & $\mathrm{H}$ & $\begin{array}{c}\text { B } \\
(\mathrm{SE})\end{array}$ & $\begin{array}{c}\beta \\
(t)\end{array}$ & $R^{2}$ \\
\hline \multirow{6}{*}{$\begin{array}{l}\text { Independent } \\
\text { Model }\end{array}$} & $\begin{array}{l}\text { Organizational } \\
\text { Commitment }\end{array}$ & $\rightarrow$ & Job Satisfaction & $\begin{array}{l}\mathrm{H}_{1} \\
\text { (c) }\end{array}$ & $\begin{array}{l}3.35 \\
(.54)\end{array}$ & $\begin{array}{c}.67 \\
(6.17 * *)\end{array}$ & .45 \\
\hline & $\mathrm{X} 2 / \mathrm{sd}=1.32$ & RMSEA = & $\mathrm{SRMR}=.03$ & \multicolumn{2}{|c|}{ GFI $=.92$} & $\mathrm{NNFI}=.98$ & $\mathrm{CFI}=.98$ \\
\hline & $\begin{array}{l}\text { Organizational } \\
\text { Commitment }\end{array}$ & $\rightarrow$ & Leadership Support & $\begin{array}{l}\mathrm{H}_{2} \\
\text { (a) }\end{array}$ & $\begin{array}{l}2,92 \\
(.44)\end{array}$ & $\begin{array}{c}.71 \\
\left(6.57^{* *}\right)\end{array}$ & .51 \\
\hline & $\mathrm{X} 2 / \mathrm{sd}=1.09$ & RMSEA = & $\mathrm{SRMR}=.03$ & \multicolumn{2}{|c|}{ GFI $=.96$} & $\mathrm{NNFI}=.99$ & $\mathrm{CFI}=.99$ \\
\hline & Leadership Support & $\rightarrow$ & Job Satisfaction & $\begin{array}{l}\mathrm{H}_{3} \\
\text { (b) }\end{array}$ & $\begin{array}{l}1,00 \\
(.08)\end{array}$ & $\begin{array}{c}.84 \\
\left(12.73^{* *}\right)\end{array}$ & .70 \\
\hline & $\mathrm{X} 2 / \mathrm{sd}=1.77$ & RMSEA = & SRMR $=.05$ & & & $\mathrm{NNFI}=.95$ & $\mathrm{CFI}=.96$ \\
\hline \multirow{2}{*}{$\begin{array}{l}\text { Mediator Variable } \\
\text { Model }\end{array}$} & $\begin{array}{l}\text { Organizational } \\
\text { Commitment }\end{array}$ & $\rightarrow$ & Job Satisfaction & $\begin{array}{l}\mathrm{H}_{4} \\
\left(c^{\prime}\right)\end{array}$ & $\begin{array}{c}.73 \\
(.50) \\
\end{array}$ & $\begin{array}{c}.15 \\
(6.60) \\
\end{array}$ & .71 \\
\hline & $\begin{array}{l}\mathrm{X} 2 / \mathrm{sd}=1.45 \\
\mathrm{ES}=.59\end{array}$ & $\begin{array}{l}\mathrm{RMSEA}= \\
\mathrm{SBT}=5.86\end{array}$ & $\begin{array}{l}\mathrm{SRMR}=.04 \\
\mathrm{R}^{2}=.37\end{array}$ & & & $\mathrm{NNFI}=.96$ & $\mathrm{CFI}=.97$ \\
\hline
\end{tabular}

$* p<.05, * * p<.01 ; \mathrm{ES}=$ Effect Size, SBT $=$ Sobel Test Statistics, $\mathrm{R}^{2}=$ Variance Caused by Indirect Effect

\section{Discussion, Conclusion and Suggestion}

In an organization, good management policies and practices in line with the expectations of employees create work effort, job satisfaction and organizational commitment at an adequate level (Odoch \& Nangoli, 2014). In order to ensure and increase the employees' commitment to the organization, it is necessary to convince the employees that they do a meaningful job, to appreciate 
the importance of their work, to make them love their work and to see them as individuals who try to reach the good and right thing with a mindset that participate in production, examine, research, think, and develop suggestions, not as a production factor that does the job given. In this context, employees need leaders who support them.

Individuals establishing a strong bond between themselves and the organization and feeling that they are a part of the organization is a result of organizational commitment (Schermerhorn, Hunt, \& Osborn, 1994). Those who have to work due to economic difficulties, do several jobs as a result of insufficient salary to survive, do a different job from their specialty, and call center employees, doctors, medical technicians, nurses, mineworkers, heavy metal and production industry workers engaged in heavy and demanding jobs can only develop a continuance commitment to their organizations. Therefore, they are not satisfied with their job that they have to do. However, employees who receive the support of the leader, which is an element of organizational support, feel more positive psychologically and physiologically.

In this research, the mediating role of leader support in the effect of organizational commitment on job satisfaction was determined. Leadership support makes the employee feel valued (Cho et al., 2009). The positive effect of leader support on job satisfaction, one of the research results, has been supported by various studies (Tsai, 2011; Griffin et al., 2001). Another result of the research is that organizational commitment positively effects job satisfaction. This result has been supported by various studies (Markovits et al., 2007; Odoch \& Nangoli, 2014).

The last result of the research is that leader support had a mediating role in the effect of organizational commitment on job satisfaction. This result is also supported by various studies (Currivan, 1999; Griffin, et al., 2001; Seo et al., 2004). Just as an individual who experiences a mental breakdown or feels psychologically uncomfortable can get psychological help, employees who have burnout or negative mood in the organization, who have the ability to do their job but do not have the courage, who are not able to implement an innovative idea they have or do not want to lose their job simply to hold on to life also need "a leader, manager or supervisor who supports" them.

This research was carried out with blue collar workers working in the textile production sector. Blue collar workers deal with problems such as work accidents, minimum wage, and union rights. They spend most of their lives on their shifts in order to be rewarded for their labor. In a tiring and weary business life, it is still not enough to be committed to their organization in order to smile and hold on to their work. Employees are a human resource, not a production resource. They are motivational creatures having feelings and emotions.

The contribution of this research to science management literature is that leaders' support is important for employees' job satisfaction especially in extraordinary situations such as economic crisis or pandemic. Leaders' support in both financial and motivational activities in difficult times will increase both employee and business productivity. Supervisors, managers and leaders should support their employees with methods such as feedback, professional development, training, valuing their ideas, listening to their problems and providing solutions, and developing alternative solutions instead of firing them. They also need to see their employees' contribution to the business and, most importantly, value them. In future studies, it is recommended to add the variables of person-organization fit, self-awareness and self-esteem in the effect of organizational commitment on job satisfaction. 


\section{References}

Ackfeldt, A. L., \& Coote, L. V. (2005). A study of organizational citizenship behaviors in a retail setting. Journal of Business Research, 58(2), 151-159.

Agnes, M., Kiarie, W., Maru, L. C., \& Cheruiyot, T. K. (2017). Leader personality traits and employee job satisfaction in the media sector, Kenya. The TQM Journal, 29(1),133-146.

Ahmad, Z. A., \& Yekta, Z. A. (2010). Relationship between perceived organizational support, leadership behavior and job satisfaction: An empirical study in Iran. Intangible Capital, 6(2), 162-184.

Allen, N. J., \& Grisaffe, D.B. (2001). Employee commitment to the organization and customer reactions, mapping the linkages. Human Resource Management Review, 11, 209-236.

Allen, N. J., \& Meyer, J. P. (1990). The measurement and antecedents of affective, continuance and normative commitment to the organization. Journal of Occupational Psychology, 63(1), 1-18.

Allen, N. J., \& Meyer, J. P. (1996). Affective, continuance and normative commitment to the organization: An examination of construct validity. Journal of Vocational Behaviour. 49, 252-276.

Amundsen, S., \& Martinsen, Q. L. (2014). Self-other agreement in empowering leadership: Relationships with leader effectiveness and subordinates' job satisfaction and turnover intention. The Leadership Quarterly, 25(4), 784-80.

Babin, B. J., \& Boles, J. S. (1996). The effects of perceived co-worker involvement and supervisor support on service provider role stress, performance and job satisfaction. Journal of Retailing, 72(1), 57-75.

Bakan, I. (2011). Foundation of organizational strategies: Organizational commitment (concept, theory, cause and effect). Ankara: Gazi Bookstore.

Baron, R. M., \& Kenny, D. A. (1986). The moderator-mediator variable distinction in social psychological research: Conceptual, strategic and statistical considerations. Journal of Personality and Social Psychology, 51(6), 1173-1182.

Başaran, I. E. (1982). Organizational behavior. Ankara: Ankara University Faculty of Educational Sciences Publication.

Bateman, T. S., \& Strasser, S. (1984). A Longitudinal analysis of the antecedents of organizational commitment. Academy of Management Journal, 27(4), 95-112.

Becker, H. S. (1960). Notes on the concept of commitment. The American Journal of Sociology, 66(1), 32-40.

Benkhoff, B. (1997). Ignoring commitment is costly: New approaches establish the missing link between commitment and performance. Human Relations, 50(6), 701-726.

Bhanthumnavin, D. (2003). Perceived social support from supervisor and group members' psychological and situational characteristics as predictors of subordinate performance in Thai work units. Human Resource Development Quarterly, 14, 74 97.

Bhuian, S. N., Al-Shammari, E. S., \& Jefri, O. A. (1996). Organizational commitment, job satisfaction and job characteristics: An empirical study of expatriates in Saudi Arabia. International Journal of Commerce and Management, 6(3/4), 57-8.

Blau, G. J., \& Boal, K. R. (1987). Conceptualizing how job involvement and organizational commitment affect turnover and absenteeism. Academy of Management Review. 12(2), 288-301.

Brewer, A. M. (1996). Developing commitment between managers and employees. Journal of Managerial Psychology, 11(4), 2434.

Büyüköztürk, Ş. (2011). Manual of data analysis for social sciences. Ankara: Pegem Academy.

Çalışkan, A. (2015). The effect of organizational justice on organizational commitment: The mediating role of ethical climate. International Journal of Economic and Administrative Sciences, 1(2), 115-141.

Çelen, Ö., Teke, A., \& Cihangiroğlu, N. (2013). The effect of organizational commitment on job satisfaction: A study in Gülhane Military Medical Faculty Teaching Hospital. Suleyman Demirel University Journal of Faculty of Economics and Administrative Sciences, 18(3), 399-41.

Chiok, F. L. J. (2001). Leadership behaviours: Effects on job satisfaction, productivity and organizational commitment. Journal of Nursing Management, 9(4), 191-204.

Cho, S., Johanson, M. M., \& Guchait, P. (2009). Employees intent to leave: A comparison of determinants of intent to leave versus intent to stay. International Journal of Hospitality Management, 28, 374-381.

Çokluk, Ö., Şekercioğlu, G., \& Büyüköztürk, Ş. (2010). Multivariate statistics for social sciences: SPSS and Lisrel applications. Ankara: Pegem Academy.

Currivan, D. B. (1999). The causal order of job satisfaction and organizational commitment in models of employee turnover. Human Resource Management Review, 9(4), 495-524.

Cüceloğlu, D. (2001). Within us, we. Istanbul: Remzi Publishing House.

Drummond, H. (2000). Introduction to organizational behavior. New York: Oxford University Press. 
Eisenberger, R., Stinglhamber, F., Vandenberghe, C., Sucharski, I. L., \& Rhoades, L. (2002). Perceived supervisor support: Contributions to perceived organizational support and employee retention. Journal of Applied Psychology, 87(3), 565-573.

Fornell, C., \& Larcker, D. F. (1981). Evaluating structural equation models with unobservable variables and measurement error. Journal of Marketing Research, 18(1), 39-5.

George, P. (2008, March). Significance of leadership in productivity management. Proceedings of the International Multiconference of Engineers and Computer Scientists, 2, 19-21. Hong Kong.

Gilstrap, J. B., \& Collins, B. J. (2012). The importance of being trustworthy: Trust as a mediator of the relationship between leader behaviors and employee job satisfaction. Journal of Leadership and Organizational Studies, 19(2), 152-163.

Green, S. G., Anderson, S. E., \& Shivers, S. L. (1996). Demographic and organizational influences on leader-member exchange and related work attitudes. Organizational Behavior Human Decision Process, 66(2), 203-214.

Griffin, M. A., Patterson, M. G., \& Michael, A. W. (2001). Job satisfaction and team work: The role of supervisor support. Journal of Organizational Behavior, 22, 537-55.

Hugnes, R. L., Gonnett, R. C., \& Curphy, G. J. (2006). Leadership, enhancing the lessons of experience (8th edition). New York: McGraw Hill.

Hui, C., Law, K. S., \& Chen, Z. X. (1999). A structural equation model of the effects of negative affectivity, leader-member exchange, and perceived job mobility on in-role and extra-role performance: A Chinese case. Organizational Behavior and Human Decision Processes, 77(1), 3-21.

Hulpia, H., Devos, G., \& Van Keer, H. (2009). The influence of distributed leadership on teachers' organizational commitment: A multilevel approach. The Journal of Educational Research, 103(1), 40-52.

Kim, W. G., Leong, J. K., \& Lee, Y. K. (2005). Effect of service orientation on job satisfaction, organizational commitment and intention of leaving in a casual dining chain restaurant. International Journal of Hospitality Management, 24(2), 171-193.

Lam, T., Zhang, H., \& Baum, T. (2001). An investigation of employees' job satisfaction: the case of hotels in Hong Kong. Tourism Management, 22(2), 157-165.

Leow, K. L., \& Khong, K. W. (2009). Organizational commitment: The study of organizational justice and leader-member exchange (LMX) among auditors in Malaysia. International Journal of Business and Information, 4(2), 161-198.

Leslie, B., Aring, M. K., \& Brand, B. (1998). Informal learning: The new frontier of employee and organizational development. Economic Development Review, 15(4), 12.

Liao, S. H., Hu, D. C., \& Chung, H. Y. (2009). The relationship between leader-member relations, job satisfaction and organizational commitment in international tourist hotels in Taiwan. The International Journal of Human Resource Management, 20(8), 1810-1826.

Locke, E. A. (1976). The nature and causes of job satisfaction. In M. D. Dunnette (Ed.). Handbook of industrial and organizational psychology (pp.1297-1349). New York, NY: McGraw-Hill.

Makanjee, C. R., Hartzer, Y. F., \& Uys, I. L. (2006). The effect of perceived organizational support on organizational commitment of diagnostic imaging radiographers. Radiography, 12(2), 118-126.

Markovits, Y., Davis, A. J., \& Van Dick, R. (2007). Organizational commitment profiles and job satisfaction among Greek private and public sector employees. International Journal of Cross Cultural Management, 7(1), 77-99.

Meyer, J. P., \& Allen, N. J. (1991). A three-component conceptualization of organizational commitment. Human Resource Management Review, 1(1), 61-89.

Meyer, J. P., Allen, N. J. \& Smith, C. A. (1993). Commitment to organizations and occupations: Extension and test of a threecomponent conceptualization. Journal of Applied Psychology, 78(4), 538-551.

Mayer, R. C., \& Schoorman, F. D. (1992). Predicting participation and production outcomes through a two-dimensional model of organizational commitment. Academy of Management Journal, 35(3), 671-684.

Mowday, R., Porter, L. W., \& Steers, R. (1982). Organizational linkages: the psychology of commitment, absenteeism and turnover. New York, NY: Academic Press.

Netemeyer, R. G, Boles J. S, Mckee D. O., \& Mcmurrian, R. (1997). An investigation into the antecedents of organizational citizenship behaviors in a personal selling context. Journal of Marketing, 61(3), 85-98.

Odoch, H., \& Nangoli, S. (2014). The effect of organizational commitment on job satisfaction in Uganda Colleges of Commerce, Issues in Business Management and Economics, 2(10), 165-171.

Omidifar, R. (2013). Leadership style, organizational commitment and job satisfaction: A case study on high school principals in Tehran, Iran. American Journal of Humanities and Social Sciences, 1(4), 263-267.

O'Reilly, C., \& Chatman J. (1986). Organizational commitment and psychological attachment: the effects of compliance, identification and internalization on prosocial behavior. Journal of Applied Psychology, 71(3), 492-499.

Osborn, R. N., \& Vicars, W. M. (1976). Sex stereotypes: An artifact in leader behavior and subordinate satisfaction analysis? Academy of Management Journal, 19(3), 439-449. 
Peng, J., Li, D., Zhang, Z., Tian, Y., Miao, D., Xiao, W., \& Zhang, J. (2016). How can core self-evaluations influence job burnout? The key roles of organizational commitment and job satisfaction. Journal of Health Psychology, 21(1), 50-59.

Pool, S., \& Pool, B. (2007). A management development model measuring organizational commitment and its impact on job satisfaction among executives in a learning organization. Journal of Management Development, 26(4), 353-369.

Porter, L. W., Steers, R. M., Mowday, R. T., \& Boultian, P. V. (1974). Organizational commitment, job satisfaction and turnover among psychiatric technicians. Journal of Applied Psychology, 59(5), 603-609.

Reid, M. F., Riemenschneider, C. K., Allen, M. W., \& Armstrong, D. J. (2008). Information technology employees in state government: A study of affective organizational commitment, job involvement and job satisfaction. The American Review of Public Administration, 38(1), 41-61.

Rhoades, L., \& Eisenberger, R. (2002). Perceived organizational support: A review of the literature. Journal of Applied Psychology, 87, 698-714.

Romzek, B. S. (1989). Personal consequences of employee commitment. Academy of Management Journal, 32(2), 649-661.

Rose, R. C., Kumar, N., \& Pak, O. G. (2009). The effect of organizational learning on organizational commitment, job satisfaction and work performance. Journal of Applied Business Research, 25(6), 55-65.

Sanecka, E. (2013). The effects of supervisors subclinical psychopathy on subordinates organizational commitment, job satisfaction and satisfaction with supervisor. The Journal of Education, Culture, and Society, 4(2), 172-191.

Schermerhorn, J. R., Hunt, J. G., \& Osborn, R. N. (1994). Managing organization behavior (5th Edition). New York, NY: John Wiley \& Sons, Inc.

Seo, Y., Ko, J., \& Price, J. L. (2004). The determinants of job satisfaction among hospital nurses: A model estimation in Korea. International Journal of Nursing Studies, 41, 437-446.

Singh, J. (2000). Performance productivity and quality of frontline employees in service organizations. Journal of Marketing, 64, $15-34$.

Sneed, J., \& Herman, C. M. (1990). Influence of job characteristics and organizational commitment on job satisfaction of hospital foodservice employees. Journal of the American Dietetic Association, 90(8), 1072-1076.

Tsai, Y. (2011). Relationship between organizational culture, leadership behavior and job satisfaction. BMC Health Services Research, 11(1), 98.

Tütüncü, Ö. (2000). Job satisfaction analysis in non-profit food and beverage businesses. Dokuz Eylül University Institute of Social Sciences Journal, 2(3), 169-181.

Van Voorhis, P., Cullen, F., Link, B., \& Wolfe, N. (1991). The impact of race and gender on correctional officers' orientation to the integrated environment. Journal of Research in Crime and Delinquency, 28, 472-50.

Vecchio, R. P (1995). Organizational behavior. Florida: The Dryden Press.

Walumbwa, F., Orwa, B., Wang, P., \& Lawler, J. (2005). Transformational leadership, organizational commitment, and job satisfaction: A comparative study of Kenyan and U.S. financial firms. Human Resource Development Quarterly, 16(2), 235257.

Ward, E. A., \& Davis, E. (1995). The effect of benefit satisfaction on organizational commitment. Compensation and Benefits Management, 11(3), 35-4.

Weiss, D. J., Dawis, R. V., \& England, G. W. (1967). Manual for the Minnesota Satisfaction Questionnaire. Minnesota Studies in Vocational Rehabilitation, 22, 12.

Whyte, W. H. (1956). The organization man. New York, NY: Simon and Schuster.

Wiener, Y. (1982). Commitment in organization a normative view. Academy of Management Review, 7(3), 418-428.

Wilson, P. A. (1995). The effects of politics and power on the organizational commitment of federal executives. Journal of Management, 21(1), 101-118.

Wilson, A., \& Frimpong, J. (2004). A reconceptualisation of the satisfaction-service performance thesis. Journal of Service Marketing, 18(6), 471-481.

Yoon, J., \& Thye, S. R. (2002). A dual process model of organizational commitment: Job satisfaction and organizational support. Work and Occupations, 29(1), 97-124.

Yousef, D. A. (2000). Organizational commitment: A mediator of the relationships of leadership behavior with job satisfaction and performance in a non-western country. Journal of Managerial Psychology, 15(1), 6-28. 